\title{
Prevalence of HBsAg and knowledge about hepatitis B in pregnancy in the Buea Health District, Cameroon: a cross-sectional study
}

\author{
Andreas A Besong Frambo, Julius Atashili, , Peter Nde Fon and Peter Martins Ndumbe
}

\begin{abstract}
Background: Although infection with Hepatitis B Virus (HBV) remains a global public health problem, little is known about its epidemiology in pregnancy in sub-Saharan Africa. This study sought to determine the prevalence of, and identify factors associated with hepatitis B surface antigen ( $\mathrm{HBsAg}$ ) positivity among pregnant women in the Buea Health District (BHD) in rural Cameroon. We also assessed pregnant women's knowledge about hepatitis B.

Methods: A cross-sectional, descriptive study was undertaken. Participants were evaluated using a structured questionnaire with clinical examination and were then screened for HBsAg using a commercial rapid diagnostic test. Assessment of knowledge was done using a hepatitis B basic knowledge summary score.

Results: Of the 176 pregnant women studied, 9.7\% (95\% Cl: 5.7\%, 15\%) tested positive for HBsAg. None of the risk factors assessed was significantly associated with HBsAg positivity. The hepatitis B knowledge summary score ranged from 0 to 12 with a mean of $1.5(S D=3.14$, median $=0, I Q R=0$ to 0 ). Only $16 \%$ of participants had scores greater than 6/12. The knowledge summary score of the participants was associated with the educational level (p-value $=0.0037$ ).

Conclusion: The high prevalence of HBsAg (9.7\%) among women of child bearing age suggests that vertical transmission of HBV may be a public health problem in Buea Health District. Knowledge of HBV among pregnant women was poor. We recommend that all pregnant women ought to be routinely screened for HBV and that health education on HBV should be provided to pregnant women especially during antenatal visits.
\end{abstract}

Keywords: Hepatitis B virus, Prevalence, HBsAg, Pregnancy, Cameroon, Knowledge

\section{Background}

Infection with the hepatitis B virus (HBV) occurs worldwide and constitutes a major public health problem [1]. Over 380 million people worldwide are chronic carriers of HBV and more than 2 million deaths occur annually from HBV related diseases [2]. Approximately 65 million of all chronically infected individuals live in Africa [3,4]. In Cameroon, recent studies reported HBV prevalence rates as high as $10.1 \%$ and $12.1 \%$ among blood donors in hospital blood banks [5,6]. The prevalence of HBsAg in pregnancy does not vary much from that in the general population [7]. In Cameroon, studies carried out by Ndumbe et al. in 1992 and Chiaramonte et al. in 1991

\footnotetext{
* Correspondence: atashili@yahoo.ie

Department of Public Health and Hygiene, Faculty of Health Sciences, University of Buea, P.O, Box, 63, Buea, Cameroon
}

revealed that the prevalence of hepatitis B surface antigen was greater than $8 \%[8,9]$. Two more recent studies in Yaounde, Cameroon, estimated the prevalence of HBsAg in pregnancy at 7.9\% (in 2005) and 7.7\% (in 2013) [10,11]. Little is known on the prevalence of hepatitis in pregnancy in non-urban areas.

The risk factors for hepatitis B infection are known to be linked to body fluids especially those with high concentration of the virus like blood, semen and vaginal secretions [12]. Traditional practices that expose people to hepatitis B infection like scarification, ear and nose piercing as well as tattoos have led to higher prevalence in certain zones but not necessarily in pregnancy [13]. The risk factors for hepatitis B infection during pregnancy vary among communities depending on the cultural practices and some traditional beliefs. In one study carried out in a
C Biomed Central

(C) 2014 Frambo et al.; licensee BioMed Central Ltd. This is an Open Access article distributed under the terms of the Creative Commons Attribution License (http://creativecommons.org/licenses/by/2.0), which permits unrestricted use, distribution, and reproduction in any medium, provided the original work is properly credited. 
Nigerian obstetric population the major risk factors identified were higher mean parity, higher number of sexual partners since sexual debut, polygamy and previous sexually transmitted infection [14]. In addition to determining prevalence, risk factors for HBV infection need to be identified in each setting in order to potentially design targeted preventive measures.

Hepatitis B virus (HBV) infection may go undetected. Unawareness of an ongoing infection delays the diagnosis of HBV-related liver disease and favors the spread of the virus [15]. In a study to assess awareness of HBV infection among patients in a clinic in Italy, it was noticed that up to $40.3 \%$ of the participants were not aware of their infection [16]. Studies to assess the knowledge of hepatitis B are more often conducted with health personnel being participants. Pregnant women too are a vulnerable group and theirs is the risk of transmitting the infection to the newborn if the mother is infectious. It is for these reasons that this study was designed to determine the prevalence of $\mathrm{HBsAg}$ among pregnant women in the BHD and to identify the risk factors associated with hepatitis B in pregnancy. The knowledge of participants about hepatitis B was also assessed in this study.

\section{Methods}

This cross-sectional, descriptive study was carried out in antenatal clinics (ANC) in the Buea Health District of Cameroon from the June to July 2012. The ANCs involved were those of the Buea Regional Hospital, Buea Road Health Center, Buea Town Health Center, Muea Subdivisional Hospital, Mile 16 Health Center and Solidarity clinic. There are other health centers found in the health district, but because of their low number of pregnant women per ANC session ( $<4$ per week) and the irregularity of their ANC sessions, they were not included in our study setting. Our study and target population was made up of pregnant women who attend ANC in the health district. The sampling method was consecutive. All pregnant women attending ANC in the health district were eligible for participation and were included if they agreed to participate. All participants who consented were interviewed using a standard questionnaire adapted from the WHO protocol for assessment of hepatitis B infection in antenatal patients [17]. Prior to use in the study participants the questionnaire was pilot tested in 16 pregnant women in our setting with the aim of revising poorly structured questions, estimate the average time required to fill the questionnaire and thus validate the use of the questionnaire in our context.

After the examination of the participant, $3 \mathrm{mls}$ of fresh venous blood was collected by venipuncture into an EDTA tube. The plasma of collected samples was tested for presence of HBsAg using a commercial hepatitis B surface antigen test strip, the DiaSpot One Step Hepatitis B test (DiaSpot Rapid Diagnosis, Jakarta, Indonesia). This required the deposition of two drops of the plasma sample onto the corresponding receiving section of the strip and waiting a minimum of five minutes before reading the test result. The test result is said to be positive when two bands appear; one in the test region and another in the control region. The test result was marked negative when one band appears in the control region and no band appears in the test region. In situations where the control region had no test band, the test was marked invalid. For invalid cases, the used strip is discarded. A new strip is gotten and the remaining blood in the EDTA test tube was used to obtain another identical sample. This was again tested in a similar manner and the result obtained recorded accordingly.

\section{Statistical analysis}

The analysis of the data was done using EPI-INFO Version 3.5.1 and MICROSOFT EXCEL-2007. The prevalence of HBsAg among the participants was the ratio between HBsAg positive samples and the total samples collected. For every potential risk factor assessed (history of surgery, history of blood transfusion, abortion, scarification, piercing, tattoos, condom use, sex partners and history of sexually transmitted infection), the risk ratio of antigen positivity comparing those with potential risk factor to those without the risk factor was determined. The statistical significance of the association between each potential risk factor and antigen positivity was assessed using a Fisher's exact test. Risk factors with $\mathrm{p}$-values $<0.05$ were to be considered significant and associated. The knowledge of hepatitis B was assessed by determining how many participants had correct responses to the questions on knowledge of hepatitis B. Each knowledge question was scored as zero (0) for incorrectly or "Don't know" responses, while correct responses were scored one (1). A knowledge summary score for the 12 questions asked was calculated from the total of correct answers. Participants with scores over 6/12 were denoted knowledgeable. Data are presented using tables.

\section{Ethical considerations}

Ethical clearance was obtained from the Faculty of Health Sciences Institutional Review Board (FHS-IRB) of the University of Buea and administrative authorization was obtained from the Regional Delegation of Public Health for the South West Region of Cameroon. Participants had the study protocol carefully explained to them and participation was voluntary. Written informed consent was obtained from all participants. All procedures were standard involving minimum risks. Study results were returned to participants and incorporated into their care by their respective providers. 


\section{Results}

\section{Participant characteristics}

The characteristics of the 176 participants enrolled are summarized in Table 1 . The ages ranged from 17 to 42 years with a mean age of $25.7 \pm 5.4$ years. The predominant age group was $25-29$ years representing $33 \%$ of the general population. The majority of the participants had completed secondary school. Thirty-six (20.7\%) of the participants were students and a greater part of the participants 94 (54\%) were employed. Amongst the married participants, 108 (62.1\%) were monogamous while 5 (2.9\%) were polygamous. Regarding gestational age and parity, majority of the participants were in the third trimester (64\%) and multigravidas comprised the majority (58.4\%) when compared with primigravidas $(31.8 \%)$ and grand multigravidas (9.8\%).

\section{Prevalence of $\mathrm{HBsAg}$}

The prevalence of HBsAg in pregnancy was found to be 9.7\% (95\% CI, 5.7 - 15.0). The highest prevalence rate

Table 1 Demographic characteristics of participants of a survey of HBsAg prevalence among pregnant women in Buea Health District

\begin{tabular}{|c|c|c|}
\hline Characteristic & $\mathrm{N}^{*}$ & Percentage \\
\hline \multicolumn{3}{|l|}{ AGE (years) } \\
\hline$<30$ & 139 & 79 \\
\hline$\geq 30$ & 37 & 21 \\
\hline \multicolumn{3}{|l|}{ Education } \\
\hline Informal & 1 & 0.6 \\
\hline Primary & 33 & 19.3 \\
\hline Secondary & 89 & 52.0 \\
\hline Tertiary & 48 & 28.1 \\
\hline \multicolumn{3}{|l|}{ Employment } \\
\hline Unemployed & 44 & 25.3 \\
\hline Employed & 94 & 54.0 \\
\hline Student & 36 & 20.7 \\
\hline \multicolumn{3}{|l|}{ Marital Status } \\
\hline Unmarried & 61 & 35.1 \\
\hline Monogamy & 108 & 62.1 \\
\hline Polygamy & 5 & 2.9 \\
\hline \multicolumn{3}{|l|}{ Gestational age } \\
\hline First trimester & 10 & 6.1 \\
\hline Second trimester & 49 & 29.9 \\
\hline Third trimester & 105 & 64.0 \\
\hline \multicolumn{3}{|l|}{ Parity } \\
\hline Primipara (1) & 55 & 31.8 \\
\hline Multipara (2-4) & 101 & 58.4 \\
\hline Grand multipara $(>4)$ & 17 & 9.8 \\
\hline
\end{tabular}

*Some item totals may not sum up to 176 because of non-response. was observed in the age group 15-19 (20\%), followed by the age group 30-34 (13.64\%). None of the assessed participant characteristics was significantly associated with HBsAg positivity (Table 2). Half of the participants with HBsAg positivity were in the third trimester and multigravidas (64.7\%) constituted the majority of HBsAg positive women. Twenty participants had right upper quadrant tenderness among whom 4 (20\%) were positive for HBsAg. No other assessed clinical feature (hepatomegaly, jaundice, palmar erythema, splenomegaly, finger clubbing, abnormal urine and stool colour) suggestive of liver disease was identified among the participants that tested positive for HBsAg.

None of the risk factors assessed in this study was significantly associated with $\mathrm{HBsAg}$ positivity. Table 3 shows the different risk factors assessed and their corresponding risk ratios and $\mathrm{p}$-values.

\section{Knowledge on hepatitis B}

Table 4 shows the responses to questions about knowledge of HBV among the pregnant women who participated in this study. As a whole, majority of the participants had never heard of the disease called hepatitis and $80 \%$ of the participants did not know that hepatitis B was a virus. Only $15.9 \%$ of the participants knew that infection with

Table 2 Prevalence of HBsAg in relation to socio-demographic and obstetrical characteristics of pregnant women attending ANC in the Buea Health District, Cameroon

\begin{tabular}{|c|c|c|c|c|c|}
\hline Factor & $\mathrm{N}$ & $\mathrm{n}$ & $\%$ & RR & $\begin{array}{l}\text { Fisher exact } \\
\text { p-value }\end{array}$ \\
\hline Age & & & & 0.81 & 1.00 \\
\hline$<30$ & 139 & 14 & 10.07 & & \\
\hline$\geq 30$ & 37 & 3 & 8.11 & & \\
\hline Education & & & & 0.74 & 0.53 \\
\hline$\leq$ Primary & 34 & 4 & 11.76 & & \\
\hline$>$ Primary & 137 & 12 & 8.76 & & \\
\hline Employment & & & & 1.22 & 0.80 \\
\hline Unemployed & 80 & 7 & 8.75 & & \\
\hline Employed & 94 & 10 & 10.64 & & \\
\hline Marital status & & & & 1.75 & 0.42 \\
\hline Unmarried & 61 & 4 & 6.56 & & \\
\hline Married & 113 & 13 & 11.50 & & \\
\hline Gestational age & & & & 0.56 & 0.27 \\
\hline$\leq 24$ weeks & 59 & 8 & 13.56 & & \\
\hline$>24$ weeks & 105 & 8 & 7.62 & & \\
\hline Parity & & & & 0 & 0.38 \\
\hline$\leq 4$ & 156 & 17 & 10.9 & & \\
\hline$>4$ & 17 & 0 & 0 & & \\
\hline
\end{tabular}


Table 3 Risk factors associated with HBsAg positivity among pregnant women in Buea Health District

\begin{tabular}{|c|c|c|c|c|c|}
\hline Risk factor & Number & Positives & Percentage & $\begin{array}{l}\text { Risk } \\
\text { ratio (RR) }\end{array}$ & $\mathrm{p}$-value \\
\hline Past surgery & & & & 0.00 & 0.23 \\
\hline No & 153 & 17 & 11.11 & & \\
\hline Yes & 21 & 0 & 0.00 & & \\
\hline Blood transfusion & & & & 0.00 & 0.61 \\
\hline No & 161 & 17 & 10.56 & & \\
\hline Yes & 12 & 0 & 0.00 & & \\
\hline Abortion & & & & 0.88 & 1.00 \\
\hline No & 118 & 12 & 10.17 & & \\
\hline Yes & 56 & 5 & 8.93 & & \\
\hline Scarification & & & & 0.84 & 0.79 \\
\hline No & 66 & 7 & 10.61 & & \\
\hline Yes & 101 & 9 & 8.91 & & \\
\hline Piercing & & & & 1.62 & 1.00 \\
\hline No & 16 & 1 & 6.25 & & \\
\hline Yes & 158 & 16 & 10.13 & & \\
\hline Tattoos & & & & 0.00 & 1.00 \\
\hline No & 142 & 15 & 10.56 & & \\
\hline Yes & 4 & 0 & 0.00 & & \\
\hline Condom use & & & & 0.00 & 1.00 \\
\hline Inconsistent & 169 & 17 & 10.06 & & \\
\hline Consistent & 7 & 0 & 0.00 & & \\
\hline Sex partners & & & & 0.71 & 1.00 \\
\hline$\leq 5$ & 159 & 16 & 10.06 & & \\
\hline$>5$ & 14 & 1 & 7.14 & & \\
\hline Past sti & & & & 0.69 & 0.46 \\
\hline No & 87 & 10 & 11.49 & & \\
\hline Yes & 88 & 7 & 7.45 & & \\
\hline
\end{tabular}

hepatitis virus affects the liver as the primary organ. The knowledge of HBV regarding transmission was equally poor as $<20 \%$ of the participants had the correct knowledge. A hundred and forty one (80.6\%) among the 176 who participated in this study did not know that an infected person is capable of living without ever presenting complaints related to the disease. Meanwhile, a smaller $2.3 \%$ had the misconception that only particular people could be affected by the hepatitis B virus. The fact that hepatitis B infection can cause liver cancer was affirmed by 28 participants $(15.9 \%)$ and $15.3 \%$ had the correct knowledge about prevention of hepatitis $\mathrm{B}$ infection by vaccination.

Out of the 176 participants, 137 (80\%) had a knowledge summary score $\leq 2$ while $7(4 \%)$ had a knowledge summary score that ranged between 3 and 5. Twenty eight (16\%) participants had a knowledge summary score $\geq 6$ and were denoted knowledgeable for HBV. Both inadequate and intermediate knowledge scores were merged and termed poor knowledge so that a cutoff value for the knowledge summary score of 6 will be considered poor knowledge. In this case $84 \%$ of the participants fell under the range of poor knowledge.

Among the demographic and obstetric characteristics, only education was significantly associated with mean KSS $(\mathrm{p}$ value $=0.0037)$.

\section{Discussion}

Screening asymptomatic people is an important instrument of disease detection, prompt diagnosis and intervention especially concerning a typically asymptomatic infection such as chronic HBV infection. Given that infected pregnant women stand the chance of transmitting the HBV infection to their newborn babies, we decided to conduct a cross-sectional study to determine what proportion of pregnant women attending ANC in Buea Health District have been affected by HBV. The information gathered from this piece of work will be used by the health care providers in the health district to make decisions in an attempt to improve on the health standards of the district as a whole, but specifically for pregnant women.

In the present study, the prevalence of HBsAg among pregnant women was found to be $9.7 \%$. This is relatively high in view of the fact that a vast majority of participants were asymptomatic. In comparison with studies from other parts of the same country, the prevalence reported in this study was higher than the $1.2 \%, 7.85 \%$ and $7.7 \%$ reported by Thumamo \&Asoquo (2004), Kfutwah et al. (2012) and Fomulu et al. (2013) respectively $[11,18,19]$. This difference may be because of different socioeconomic status and the natural difference attached to different geographic zones. Our prevalence was also higher than the $5.4 \%$ reported in the early nineties by Ndumbe et al. in rural pregnant women in Cameroon [20]. We had similar results with Okoth et al. in Kenya, who found prevalence of 9.3\% [21]. Similar results were also recorded by Makuwa et al. who found a prevalence of $9.2 \%$ in Gabon [22]. These similarities could be explained by the fact that it is the same risk group that was studied and also the test used was similar in principle to the one we used in our study. We however expected this high prevalence and this is in conformity with the established fact that HBsAg is endemic in African countries south of the Sahara desert of which Cameroon is among [8]. This level of carrier state in women of reproductive age will suggest that there is a high risk of mother-to-infant transmission in the Buea Health District. However, HBsAg carrier state alone in a pregnant woman does not put the foetus at a huge risk of being infected, instead, pregnant women who are 
Table 4 Knowledge of HBV among pregnant women attending ANC in the Buea Health District, Cameroon

\begin{tabular}{|c|c|c|c|}
\hline Knowledge question & No (\%) & Yes (\%) & Don't know (\%) \\
\hline Is hepatitis B a virus? & $5(2.9)$ & $30(17.1)$ & $140(80)$ \\
\hline Does hepatitis B affect the liver? & $5(2.8)$ & $28(15.9)$ & $143(81.3)$ \\
\hline Can hepatitis B be transmitted through unsterilized needles, blades and other sharp material? & $6(3.8)$ & $22(12.5)$ & $148(84.1)$ \\
\hline Can hepatitis B be transmitted by contaminated blood and blood products? & $4(2.3)$ & $29(16.5)$ & $143(81.3)$ \\
\hline Is hepatitis B transmitted through unsafe sex? & $7(4.0)$ & $24(13.7)$ & $144(82.3)$ \\
\hline Can hepatitis B be transmitted through kissing? & $16(10.9)$ & $19(15.0)$ & $140(80)$ \\
\hline Can an infected person remain without symptoms? & $14(8.0)$ & $20(11.4)$ & $141(80.6)$ \\
\hline Can hepatitis B affect any person? & $4(2.3)$ & $32(18.2)$ & $140(79.5)$ \\
\hline Will an infected person remain infected for life? & $18(11.4)$ & $10(8.0)$ & $146(80.6)$ \\
\hline Is a specific diet required for all infected persons? & $12(6.9)$ & $10(5.7)$ & $153(87.4)$ \\
\hline Can hepatitis B infection cause liver cancer? & $4(2.3)$ & $28(15.9)$ & $144(81.8)$ \\
\hline Can hepatitis B be prevented by vaccination? & $6(3.4)$ & $27(15.34)$ & $143(81.3)$ \\
\hline
\end{tabular}

Note. Knowledge of HBV was assessed by assigning a point for every correct answer only. Points ranged from 0 to 12 with a mean of $1.5 \pm 3.14$ (median $=0, \mathrm{IQR}=$ 0 to 0 ). Scores $\leq 2$ were considered inadequate while scores within 3 and 5 were considered intermediate. Scores $\geq 6$ were considered adequate and acceptable.

positive both for HBsAg and $\mathrm{HBeAg}$ are more likely to infect their babies. Transmission does not only depend of HBsAg and HBeAg status but also on anti-HBeAg status - anti-HBeAg positivitiy tends to prevent transmission [23-25]. It is estimated that transmission rates can be as high as $12 \%, 25 \%$ and $70-90 \%$ respectively in HBeAg negative/anti-HBe positive mothers, HBeAg negative/anti-HBe negative mothers and HBeAg positive/anti-HBe negative mothers [26]. Other studies have suggested that as many as $41 \%$ of $\mathrm{HBsAg}$ pregnant women are also HBeAg positive [27]. If this were the case in the BHD then the risk of vertical transmission in this setting will still be high. More accurate estimates of the risk of mother-to-infant transmission will however require a study of $\mathrm{HBsAg}, \mathrm{HBeAg}$, anti-HBeAg levels and HBV_DNA levels (when possible) in pregnant women in the Buea Health district. Given the unavailability of the hepatitis B immune globulin (HBIG) in many developing countries, the use of the hepatitis $B$ vaccine alone is recommended and considered appropriate treatment to prevent many cases of HBV during the perinatal period - the period of highest risk of chronicity [28].

We did not identify significant risk factors associated with HBsAg positivity in our study. This is contrary to many studies carried out elsewhere as most often at least one risk factor is identified. Blood transfusion was identified as the single risk factor for HBsAg positivity in Mexico by Cisneros-Castolo et al. [29]. Rabiu et al., identified three risk factors associated with HBsAg positivity in Nigeria (early age of sexual debut, history of multiple sexual partners and history of sexually transmitted infection) [30]. In a more recent study in urban Cameroon, only a history of contact with a jaundiced or HBV-infected person was identified as a significant predictor of current HBsAg positivity [11]. From these studies, it is evident that different regions have different risk factors associated with HBsAg positivity. Nevertheless, blood transfusion still remains a risk factor for hepatitis B transmission irrespective of the region, due to undetected donors with early acute infection, resolving infection, silent infection or infection with atypical virus serology [31]. The main reason why we think we did not identify risk factors associated was probably because our sample size was small and was statistically determined for prevalence, not for risk factors. Also it could be that the risk factors we assessed are not among the risk factors associated with HBsAg positivity in Buea Health District. Furthermore, because participants could not possibly remember what happened to them at birth and childhood, we could not assess two important risk factors associated with chronic carrier status: being borne of an HBV-positive mother and early contact in childhood with HBV [32,33].

Apart from right upper quadrant tenderness which was reported in one in five HBsAg-positive participants, all other typical symptoms of hepatitis were rare. This is not surprising as it confirms the chronic rather than acute nature of the infection in these women.

Our result document very low levels of knowledge about HBV infection among pregnant women who attend ANC in Buea health district in general. Specifically we noticed that more than $80 \%$ of our participants did not know hepatitis B was a disease caused by a virus until it was explained to them. Such low knowledge was also observed in Seattle, Washington, by Taylor and colleagues [34]. Furthermore, well above $80 \%$ of our respondents had no knowledge of the different methods of transmission of HBV until it was explained to them in terms of similarity of transmission with HIV with the 
emphasis on higher infectivity associated with HBV when compared to HIV. This is similar to earlier studies carried out by Sharma et al. [35]. The magnitude of awareness regarding $\mathrm{HBV}$ transmission has generally been observed to be quite lower than HIV though both have similar modes of transmission, even in studies on different risk groups like barbers and patients on dialysis. This difference in knowledge and precisely the low level of awareness of HBV is probably because of the lack of formal education available about HBV as compared to other diseases of similar modes of transmission and burden. Majority of our respondents did not know that most HBV carriers are asymptomatic and could transmit the virus to an uninfected person through sexual intercourse. The fact that HBV can affect any person was known to most of our participants. Overall the poor knowledge shown in this study is in line with findings from Pakistan [36] and around the globe [34,37]. This deficient knowledge warrants the need for sustained and continuous education not only about HBV but other diseases of similar magnitude and burden.

A number of limitations need to be considered in interpreting these findings. First, only $\mathrm{HBsAg}$ was tested as a marker for hepatitis B infection. Other markers exist which if combined with HBsAg could have been more reliable. As such this study only determined the prevalence of HBsAg in pregnancy in our locality. It did not permit the calculation of the risk of mother-to-child HBV transmission. Furthermore considering the crosssectional design, it is not possible to rule out or infer any cause-effect relationship between the factors assessed and HBsAg positivity. Studying self-reported knowledge is itself a limitation as one cannot rely totally on the information provided by the participants because of recall bias and social desirability bias. The use of a rapid test (less sensitive when compared to ELISA and PCR tests) may also have resulted in an underestimation of the prevalence of HBsAg.

\section{Conclusion}

Hepatitis B virus infection is a public health problem in Buea Health District. A 9.7\% prevalence of HBsAg in an apparently healthy population of pregnant women attending ANC was recorded in this study. None of the risk factors assessed was significant for HBsAg positivity. Further studies using a larger sample size will be needed to assess the risk of mother-to-child transmission of $\mathrm{HBV}$ in this setting. If these high prevalence rates are confirmed, then the public health policies to reduce the burden of HBV, including universal immunisation, and screening in high risk groups, need to be reinforced. Only $16 \%$ of the pregnant women were knowledgeable about HBV. More than $80 \%$ had misconceptions regarding the methods of transmission of HBV. While keeping in view the global burden of HBV, it is important to focus on women of child- bearing age and educate them on HBV and its prevention.

\section{Abbreviations}

ANC: Antenatal clinic; BHD: Buea Health District; Cl: Confidence interval; EDTA: Ethylenediaminetetraacetic acid; HBIG: Hepatitis B immune globulin; HBsAg: Hepatitis B surface antigen; HBV: Hepatitis B virus; HIV: Human immunodeficiency Virus; KSS: Knowledge summary score; mls: Millilitres; SD: Standard deviation; WHO: World Health Organization.

\section{Competing interests}

The authors declare that they have no competing interests.

\section{Authors' contributions}

$A A B F, J A, P N F$, and PMN conceived and designed the study. AABF implemented the study. AABF and JA conducted data analysis. AABF, JA, and PNF interpreted study results: AABF wrote the first draft of the manuscript. $J A, P N F$, and PMN reviewed and corrected the draft manuscript. All authors read and approved the final manuscript.

\section{Acknowledgements}

We thank all the study participants for the time spent in answering the questions.

Received: 11 April 2013 Accepted: 20 June 2014

Published: 25 June 2014

\section{References}

1. WHO: Hepatitis B. Fact Sheet No. 204. Geneva, Switzerland: World Health Organization; 2011.

2. Teo E-K, Lok ASF: Epidemiology, transmission, and prevention of hepatitis $B$ virus infection. In UpToDate. Edited by Basow DS. Waltham, MA: UpToDate; 2009.

3. WHO: Hepatitis B vaccines. Relevé Épidémiologique Hebd Sect Hygiène Secrétariat Société Nations Wkly Epidemiol Rec Health Sect Secr Leag Nations 2004, 79:255-263.

4. Kramvis A, Kew MC: Epidemiology of hepatitis B virus in Africa, its genotypes and clinical associations of genotypes. Hepatol Res 2007, 37:S9-S19.

5. Fouelifack Ymele F, Keugoung B, Fouedjio JH, Kouam N, Mendibi S, Dongtsa Mabou J: High Rates of Hepatitis B and C and HIV Infections among Blood Donors in Cameroon: A Proposed Blood Screening Algorithm for Blood Donors in Resource-Limited Settings. J Blood Transfus 2012, 2012:1-7.

6. Noubiap JJN, Joko WYA, Nansseu JRN, Tene UG, Siaka C: Seroepidemiology of human immunodeficiency virus, hepatitis $B$ and $C$ viruses, and syphilis infections among first-time blood donors in Edéa, Cameroon. Int J Infect Dis 2013, 17:e832-e837.

7. Euler GL, Wooten KG, Baughman AL, Williams WW: Hepatitis B surface antigen prevalence among pregnant women in urban areas: implications for testing, reporting, and preventing perinatal transmission. Pediatrics 2003, 111(Supplement 1):1192-1197.

8. Ndumbe PM, Andela A, Nkemnkeng-Asong J, Watonsi E, Nyambi P: Prevalence of infections affecting the child among pregnant women in Yaounde, Cameroon. Med Microbiol Immunol (Berl) 1992, 181:127-130.

9. Chiaramonte M, Stroffolini T, Ngatchu T, Rapicetta M, Lantum D, Kaptue L, Chionne P, Conti S, Sarrecchia B, Naccarato R: Hepatitis B virus infection in Cameroon: a seroepidemiological survey in city school children. J Med Virol 1991, 33:95-99.

10. Njouom R, Pasquier C, Ayouba A, Tejiokem MC, Vessiere A, Mfoupouendoun J, Tene G, Eteki N, Lobe MM, Izopet J: Low risk of mother-to-child transmission of hepatitis C virus in Yaounde, Cameroon: the ANRS 1262 study. Am J Trop Med Hyg 2005, 73:460-466.

11. Fomulu NJ, Morfaw FL, Torimiro JN, Nana P, Koh MV, William T: Prevalence, correlates and pattern of Hepatitis B among antenatal clinic attenders in Yaounde-Cameroon: is perinatal transmission of HBV neglected in Cameroon? BMC Pregnancy Childbirth 2013, 13:1-10.

12. Parry E, Godfrey R, Mabey D, Gill G: Hepatitis Viruses. In Princ Med Afr. 3rd edition. Cambridge: Cambridge University Press; 2009:710-712. 
13. Dwivedi M, Misra SP, Misra V, Pandey A, Pant S, Singh R, Verma M: Seroprevalence of hepatitis B infection during pregnancy and risk of perinatal transmission. Indian J Gastroenterol 2011, 30:66-71.

14. Obi SN, Onah HE, Ezugwu FO: Risk factors for hepatitis B infection during pregnancy in a Nigerian obstetric population. J Obstet Gynecol 2006, 26:770-772.

15. Vázquez-Martínez JL, Coreño-Juárez MO, Montaño-Estrada LF, Attlan M, Gómez-Dantés H: Seroprevalencia de hepatitis B en mujeres embarazadas en México. Salud Pública México 2003, 45:165-170.

16. Ippolito AM, Niro GA, Fontana R, Lotti G, Gioffreda D, Valvano MR, lacobellis A, Di Mauro L, Stroffolini T, Andriulli A: Unawareness of HBV infection among inpatients in a Southern Italian hospital. J Viral Hepat 2011, 18:e206-e211.

17. World Health Organization: Expanded Programme on Immunization. Protocol for Assessing Prevalence of Hepatitis B Infection in Antenatal Patients. Geneva: WHO; 1990. WHO/EPI/GEN/90.6.

18. Thumamo PB, Asoquo AE: Hepatitis B Surface Antigen ( $\mathrm{HBsAg}$ ) in Female Students and Pregnant Women in the West Province of Cameroon. Mary Slessor J Med 2005, 4:53-57.

19. Kfutwah AK, Tejiokem MC, Njouom R: A low proportion of HBeAg among HBsAg-positive pregnant women with known HIV status could suggest low perinatal transmission of HBV in Cameroon. Virol J 2012, 9:422X-9.

20. Ndumbe PM, Skalsky J, Joller-Jemelka H: Seroprevalence of hepatitis and HIV infection among rural pregnant women in Cameroon. Apmis 1994, 102:662-666.

21. Okoth F, Mbuthia J, Gatheru Z, Murila F, Kanyingi F, Mugo F, Esamai F, Alavi Z, Otieno J, Kiambati H: Seroprevalence of hepatitis B markers in pregnant women in Kenya. East Afr Med J 2009, 83:485-493.

22. Makuwa $M$, Caron $M$, Souquière $S$, Malonga-Mouelet $G$, Mahé $A$, Kazanji $M$ : Prevalence and genetic diversity of hepatitis $B$ and delta viruses in pregnant women in Gabon: molecular evidence that hepatitis delta virus clade 8 originates from and is endemic in central Africa. J Clin Microbiol 2008, 46:754-756.

23. Okada K, Kamiyama I, Inomata M, Imai M, Miyakawa Y, Mayumi M: e antigen and anti-e in the serum of asymptomatic carrier mothers as indicators of positive and negative transmission of hepatitis B virus to their infants. N Engl J Med 1976, 294:746-749.

24. BEASLEY RP, TREPO C, STEVENS CE, SZMUNESS W: The e antigen and vertical transmission of hepatitis B surface antigen. Am J Epidemiol 1977, 105:94-98.

25. Wong W, Reesink H, Ip HH, Nco Lelie P, Reerink-Brongers E, Yeung CY, Ma HK: Prevention of the HBsAg carrier state in newborn infants of mothers who are chronic carriers of $\mathrm{HBsAg}$ and $\mathrm{HBeAg}$ by administration of hepatitis-B vaccine and hepatitis-B immunoglobulin: double-blind randomised placebo-controlled study. Lancet 1984, 323:921-926.

26. Borgia G, Carleo MA, Gaeta GB, Gentile I: Hepatitis B in pregnancy. World J Gastroenterol WJG 2012, 18:4677.

27. WHO: Hepatitis B. Immunization of newborn infants. Relevé Épidémiologique Hebd Sect Hygiène Secrétariat Société Nations Wkly Epidemiol Rec Health Sect Secr Leag Nations 1992, 67:208-210.

28. Mast EE, Margolis HS, Fiore AE, Brink EW, Goldstein ST, Wang SA, Moyer LA Bell BP, Alter MJ: A comprehensive immunization strategy to eliminate transmission of hepatitis B virus infection in the United States. MMWR 2005, 54:1-32

29. Cisneros-Castolo $M$, Hernández-Ruiz L, Ibarra-Robles IE, Fernandez-Garate $\mathrm{RH}$, Escobedo-De La Peña J: Prevalence of hepatitis B virus infection and related risk factors in a rural community of Mexico. Am J Trop Med Hyg 2001, 65:759-763.

30. Rabiu KA, Akinola OI, Adewunmi AA, Omololu OM, Ojo TO: Risk factors for hepatitis B virus infection among pregnant women in Lagos, Nigeria. Acta Obstet Gynecol Scand 2010, 89:1024-1028.

31. Kitchen A: Hepatitis B and blood safety. Vaccine 1998, 16:S34-S37.

32. Tran $\Pi$ : Management of hepatitis $B$ in pregnancy: weighing the options. Cleve Clin J Med 2009, 76(Suppl 3):S25-S29.

33. Borgia G, Gentile I: Treating chronic hepatitis B: today and tomorrow. Curr Med Chem 2006, 13:2839-2855.

34. Taylor VM, Jackson JC, Chan N, Kuniyuki A, Yasui Y: Hepatitis B knowledge and practices among Cambodian American women in Seattle, Washington. J Community Health 2002, 27:151-163.
35. Sharma R, Sharma CL, Khajuria R: The knowledge, attitude and practices regarding $\mathrm{HBV}$ infection of married women in the reproductive Age group living in cantonment Area Sunjawan Jammu. J Med Educ Res 2004, 6:127-130.

36. Talpur AA, Memon NA, Solangi RA, Ghumro AA: Knowledge and attitude of patients towards hepatitis B and C. Pak J Surg 2007, 23:162-165.

37. Cheung J, Lee TK, Teh C-Z, Wang CY, Kwan WC, Yoshida EM: Cross-sectional study of hepatitis B awareness among Chinese and Southeast Asian Canadians in the Vancouver-Richmond community. Can J Gastroenterol J Can Gastroenterol 2005, 19:245-249.

\section{doi:10.1186/1756-0500-7-394}

Cite this article as: Frambo et al:: Prevalence of HBsAg and knowledge about hepatitis B in pregnancy in the Buea Health District, Cameroon: a cross-sectional study. BMC Research Notes 2014 7:394.

\section{Submit your next manuscript to BioMed Central and take full advantage of:}

- Convenient online submission

- Thorough peer review

- No space constraints or color figure charges

- Immediate publication on acceptance

- Inclusion in PubMed, CAS, Scopus and Google Scholar

- Research which is freely available for redistribution

Submit your manuscript at www.biomedcentral.com/submit
C Biomed Central 